\title{
Variation in the function of Eagle Owl vocal behaviour: territorial defence and intra-pair communication?
}

\author{
Vincenzo Penteriani \\ Departamento de Biología Aplicada, Estación Biológica de Doñana (EBD), C.S.I.C., \\ Avda. de María Luisa s/n., Pabellón del Perú, Apdo. 1056, 41013 Sevilla, Spain \\ (E-mail: penteriani@ebd.csic.es)
}

\begin{abstract}
The main aim of this work was to investigate the possibility that in territorial males of a species present throughout the year on their territory with their mate, there are manifest differences in the call functions within the call period. I listened monthly to dusk call displays of 17 Eagle Owl Bubo bubo males from early October to mid-February. Two different call periods exist in this species: in the first (October-December), the territorial function seems to be predominant, whereas in the second (January-February), calling related to mating prevails. Actually, in this latter period the behaviour of both male and female changes: both mate duets and number of copulations after them increase, and the choice of song posts and male vocal behaviour are different. The call functions are discussed in terms of the male-announcement, female-reproduction and territoryestablishment hypotheses.
\end{abstract}

KEY WORDS: vocal displays, call functions, territorial function, sexual function, eagle owl, Bubo bubo.

\section{INTRODUCTION}

It is widely accepted that vocal displays have two different functions: territorial defence (intra-sexual selection) and female attraction (inter-sexual selection) (e.g., Thorpe 1961, Catchpole \& Slater 1995, Kroodsma \& Miller 1996, Nemeth 1996). Although there is a huge literature on the relationship between song and territory, male songs have mainly been explained in the context of inter-sexual selection, e.g., females choose males that sing more because they are likely to be in better condition, and males cease singing when they have obtained a mate (REYER \& SChMidl 1988, Hanski \& Laurila 1993, BeAni \& Dessì-Fulgheri 1995, CATChPole \& Slater 1995, Johnstone 1995, Kroodsma \& Miller 1996, Butchart et al. 1999). In my opinion this finding is essentially dependent on the fact that the species studied were generally characterised by short-term pair-bond and territoriality, as well as frequent extra-pair copulations (hereafter EPCs). However, MøLLER (1988) clearly showed that birdsong might have additional functions, and some findings dealing 
with other functions of calling have recently been presented (Appleby et al. 1999, Göth et al. 1999, Hall \& Magrath 2000).

In monogamous long-lived species, in which the pair bond and territoriality are year-round and may persist over several years, we can hypothesise different patterns of call behaviour and functions. Actually, because animals also communicate for the sake of managing a social environment, we can hypothesise that they act differently if the message needs to be received by the mate, other conspecifics or both.

The aim of this work was to investigate the hypothesis that, in long-lived, territorial, already-mated species such as Eagle Owls Bubo bubo, that are present throughout the year in their territory with their mate, there are differences in call functions within the period from the renewal of call activity (early Autumn) to egglaying (late Winter). In this species, the main territorial defence is performed by males, which are much more vocal than females (PENTERIANi 1996). I tested the hypothesis that the pre-laying period of male vocal displays is characterised by two distinct and successive phases (with distinct vocal display behaviour and significance): (a) a territorial phase, when vocal displays are mainly directed to male conspecifics, and (b) a sexual phase, when the vocalisations are also addressed to the female to obtain copulation.

\section{METHODS}

Study area and data collection

The study was conducted from October 1999 to February 2000 on Luberon mountain in southern France $\left(43^{\circ} 53^{\prime} \mathrm{N}, 5^{\circ} 24^{\prime} \mathrm{E}\right)$. Elevation ranged from $160 \mathrm{~m}$ in the Durance river valley to $1125 \mathrm{~m}$ on Grand Luberon ridge. The study area included a mosaic of rock cliff, shrub vegetation (Quercus coccifera, Thymus vulgaris and Rosmarinus officinalis), Mediterranean forest (Quercus ilex, Q. pubescens and Pinus halepensis), crops, pastures and fallow fields.

Before the present study, a census of the breeding pairs of the whole massif was made (PENTERIANi et al. 2001, 2002), and also previously observed the calling behaviour and lifecycle of the species (1997-1999). Because divorces are not recorded in this monogamous, long-lived species, and fidelity to one breeding area was shown over several years (see review in Penteriani 1996), I chose 17 nest sites distributed over the whole study area, where I observed the dusk activity of the males. I was able to collect information on dusk movements related to the calling activity of each individual, location and use of their call perches, as well as inter- and intra-sexual calling behaviour. Moreover, I could verify that all the chosen pairs were relatively synchronized in their egg-laying date, to avoid a different life-cycle affecting vocal behaviour.

I carried out 17 listening sessions per month, 1 night per territory, for 5 consecutive months from early October, the time of renewal of call activity, to mid-February, when the owls start egg-laying (PENTERIANI et al. 2001, 2002). My passive auditory sessions (PENTERIANI et al. 2000) started $1 \mathrm{hr}$ before sunset and ended $2 \mathrm{hr}$ after sunset, by which time males left their song-posts for their hunting territories and temporarily ceased their vocal displays. Sunset is one of the two main peaks of the daily call activity of Eagle Owls, the other being during sunrise (PENTERIANi unpublished data). During each listening session, and always from the same locations and distance $(<500 \mathrm{~m}$ from the nesting cliff), I collected the following data: (1) duration of the vocal bout (a series of the single oohu, the main hoot of adult males, determined by a stopwatch, thereafter named duration of vocalisations); I defined the end of a bout as the last call heard $>60 \mathrm{sec}$ before the next call (i.e. 1 min of silence between calls was regarded as a dividing unit of time); (2) position of the call-posts: in a dominant position (on the top or on the upper half of a cliff) or on the lower half of a cliff; (3) presence/absence 
of the contemporaneous call activity of the female (the typical $u$ - $h u$, which is more distinctly disyllabic and higher pitched than that of the male, PENTERIANi 1996); (4) sunset copulations immediately following joint calling.

I did not conduct observations on windy, cloudy or rainy days because of the interference of these conditions with call displays and the starting time of calling activity (PENTERIANI unpublished data).

\section{Statistical analyses}

I separated the 5 months of call behaviour observation into two different periods, territorial and sexual, on the basis of precedent observations on female call behaviour and copulation frequencies that followed the dusk duets (female behaviour was considered to be a key to understand call patterns, Slagsvold et al. 1994) during the period 1997-1999 (Penteriani unpublished data). Because January and February were two months showing a marked increase in female responses to male call bouts and in copulations following joint calling, I hypothesised that this period could represent the threshold separating a call period mainly characterised by territorial function from the one in which sexual function became important. Consequently, and to determine if it would be really possible to discriminate the territorial from the sexual period, I tested (Mann-Whitney U-test and $c^{2}$ ) the differences between the two periods for: (1) occurrence of at least one copulation immediately following mate vocal duets; (2) frequency of female call displays related to male calling; (3) spatial distribution over the territory of the 89 call-posts that the males used during the study period. I assumed that the Eagle Owls would choose a song-post high above the nesting territory if the territorial function were the main purpose of calling (i.e., optimising both sound transmission to neighbouring receivers and reception of long distance calls from conspecifics), but would choose call-posts near the position of the female at dusk (mainly in the middle part of the nesting cliff and not in a dominant position, PENTERIANi unpublished data) if the sexual function were more important (MøLLER 1988, 1991). The choice of a test for independent values (points 1 and 2) was due to the fact that I never obtained more than 1 observation per individual for copulation following duets and female responses. I used the Wilcoxon Signed Rank Test to examine possible variation in the duration of vocalisations of the same male $(n=11)$ during the territorial vs sexual period (inter-period differences in vocal behaviour).

Several analyses were run on: (1) a sub-sample of the overall data set, for which it was possible to collect the information necessary to perform each of the different statistical procedures; (2) means when it was necessary to avoid pseudoreplication. All tests were two-tailed.

\section{RESULTS}

The frequency of female responses to the male calls was significantly more from January to mid-February $(\mathrm{n}=11)$ than in the October-December period $(\mathrm{z}=-$ 1.777, $P=0.05, \mathrm{n}=4$; Mann-Whitney U-test; see Fig. 1 for the monthly detail). Significantly more copulations following mate duets were observed at dusk from January to mid-February $(\mathrm{n}=11)$, than in the period October-December $(\mathrm{z}=-1.936, P$ $=0.05, \mathrm{n}=2$; Mann-Whitney U-test; see Fig. 1 for the monthly detail). The choice of the call-posts was significantly different between the months $\left(\mathrm{c}^{2}=74.3, P=\right.$ $0.0001, \mathrm{n}=89$ ), the males mainly choosing their posts (rocks or trees) on the dominant part of the cliffs surrounding their nest in the period October-December.

Moreover, it is possible to identify two different patterns of call displays associated with these two periods ( $n=172$ obs). During the territorial period, the male generally started the dusk vocalisations on an elevated post located on or near the 


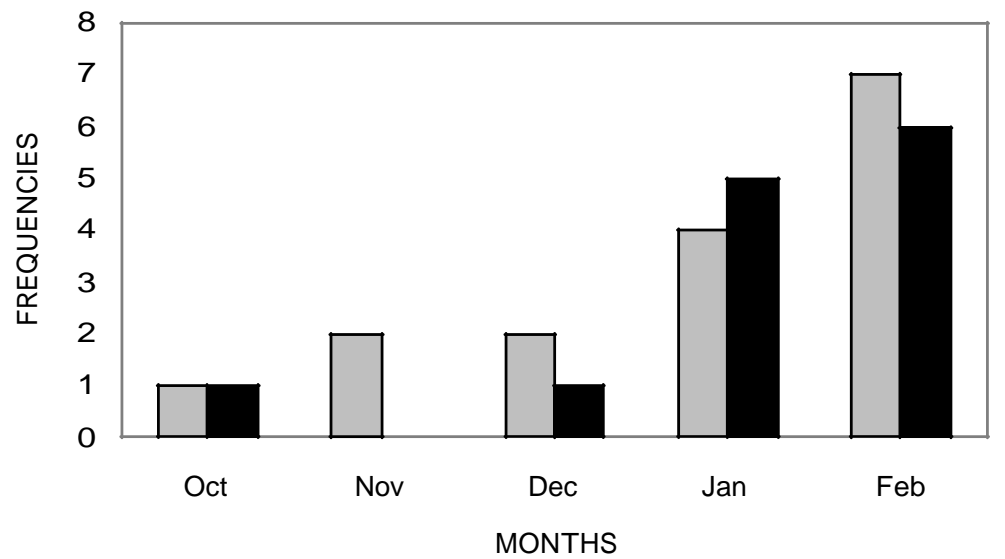

Fig. 1. - Frequencies per month of Eagle Owl female responses to male call bouts (grey bars) and copulations following call duets (black bars).

nesting cliff, and then move successively to several other habitual call-posts in the area surrounding the nest (from several hundred metres up to $2 \mathrm{~km}$ ). These callposts were generally several hundred metres from those of neighbouring male Eagle Owls (nesting at less than $2 \mathrm{~km}$ ), so that it was possible to hear up to 3-4 males calling every day. Mate duets were rare during this period. During the sexual period, although male-male calling or males calling in groups persisted (i.e., territorial function), female call displays and mate duets increased, and males spent more time in close-range courtship dialogues (lower volume vocalisations near the female and on posts which were not necessarily high up) and finally mating (usually preceded by duets).

The changing behaviour between these two periods is also seen in the significant increase in the duration of male vocalisations $(\mathrm{z}=-2.201, P=0.028, \mathrm{n}=11$; Wilcoxon Signed Ranks test) from the territorial $(1144.6 \pm 875.9 \mathrm{sec}$, range $=30$ $2100)$ to the sexual $(2468.7 \pm 1675.0 .6 \mathrm{sec}$, range $=280-4472.0)$ period .

\section{DISCUSSION}

Analysis of the dusk call displays of male Eagle Owls during the pre-laying period highlighted the presence of two different call periods, relatively well separated in time and function: early during the call period (from October to December), and in accord with the territory-establishment hypothesis (MøLLER 1988), the territorial function seems to be predominant, whereas from January to February calling related to mating prevails. In this latter period the behaviour of both male and female changes: both mate duets and number of subsequent copulations increase, and the choice of song posts and male vocal behaviour are different. An analogous differentiation in vocal behaviour between two distinct periods was observed for the singing styles of Reed Buntings Emberiza schoeniclus (NEMETH 1996). The result I obtained does not mean that the two functions and contexts are really distinct and 
well separated but rather that, depending on the stage of the breeding season, one of the two main call functions may be prevalent or be added to the other (e.g. when approaching the female fertile period). Because all the birds were already mated, calls were not used in mate choice per se, and probably were not used in mate evaluation because of the low rate of EPC and the absence of divorce in the breeding season (DALBECK et al. 1998). In addition to reinforcing territorial defence, the higher call rates observed during the sexual period could have the function of: (a) mate guarding (MøLLER 1991); (b) stimulation of ovarian development and copulation behaviour by the mate (female-reproduction hypothesis; BRockWAY 1965, MORTON et al. 1985, MøLler 1991); and (c) maintenance and consolidation of pair-bond (KLATT \& Ritchison 1993). During the month preceding egg-laying, I observed several closerange male-female courtship dialogues followed by copulation. The vocal displays at dusk may correspond with a peak of female fertility (MACE 1988, MøLler 1991).

The male-announcement hypothesis (MøLLER 1991) predicts that in birds unable to guard their mates closely to prevent EPC (because females rely on their mate for food throughout the fertile period), announcement of female fertility could be disadvantageous. The observed calling patterns of the Eagle Owl, as well as the patterns showed by other bird species (HANSKI \& LAURILA 1993, RODRIGUes 1996, GIL et al. 1999), seem not to agree with this hypothesis on the announcement of female fertility. Several birds of prey and owls are known to cease or decrease call displays after mate acquisition (MøLLER 1991). The contemporaneous call activity of breeding males could itself prevent EPC between neighbours, whereas the pair-bond characterising Eagle Owls could reduce EPC with non-territorial floaters: in several species the female tends to avoid copulations with other males (e.g., WhitTINGHAM et al. 1992, KoRPIMÄKI et al. 1996). Another possibility is that males announcing their high quality by longer-lasting long-distance calling suffer fewer territorial intrusions, because they are recognised by neighbours and eavesdropping floaters as good defenders of their mates.

My results highlight the need to approach the study of calling behaviour from a perspective different to that of birdsong only. We need more research on permanently paired and territorial species, for which mate attraction is usually an infrequent event in a bird's life, and the forces affecting song evolution are balanced toward sources of selection other than those only related to mate acquisition.

Several authors have proposed duration of vocalisations as an honest signal of the phenotypic and genetic quality of individuals (and of their territory), because high-quality males (or males in high-quality territory) can bear singing costs better than low-quality individuals (or individuals in low-quality territories) (e.g., CATCHPOle \& Slater 1995, Kroodsma \& Miller 1996). However, such studies have tended to make assumptions about the context and function of the communication of the species without considering a possible effect of the period in which vocalisations were analysed. In the light of my results, it is essential to record the call displays of different individuals in exactly the same period. Otherwise, any inter-individual differences in calling behaviour found could be due to call function changing with the stage of the breeding season rather than to individual quality.

\section{ACKNOWLEDGEMENTS}

I thank H. Cazassus, M. Gallardo, F. Liberatori and M. Melletti for their help in the field research. I am grateful for the comments provided by C. Alonso-Alvarez, J.A. 
Donázar, M. Ferrer, J.A. Martinez, D. Serrano and two anonymous referees. This study was supported by a grant of the Regional Park of Luberon (France) and of the Estación Biológica de Doñana/Consejo Superior de la Investigación Científica (Spain).

\section{REFERENCES}

Appleby B.M., Yamaguchi N. \& Macdonald D.W. 1999. Sex-specific territorial responses in Tawny Owls Strix aluco. Ibis 141: 91-99.

Beani L. \& Dessì-Fulgheri F. 1995. Mate choice in the grey partridge, Perdix perdix: role of physical and behavioural traits. Animal Behaviour 49: 347-356.

BrockWAY B.F. 1965. Stimulation of ovarian development and egg-laying by male courtship vocalizations in budgerigars, Melopsittacus undulatus. Animal Behaviour 26: 622-629.

Butchart S.H.M., Seddon N. \& Eкstrom J.M.M. 1999. Yelling for sex: harem males compete for female access in bronze-winged jacanas. Animal Behaviour 57: 637-646.

Catchpole C.K. \& Slater P.J.B. 1995. Bird song. Biological themes and variations. Cambridge: Cambridge University Press.

Dalbeck L., Bergerhausen W. \& Krishner O. 1998. Telemetriestudie zur Orts- und Partnertreue beim Uhu Bubo bubo. Vogelwelt 119: 337-344.

Gil D., Graves J.A. \& Slater P.J.B. 1999. Seasonal patterns of singing in the willow warbler: evidence against the fertility announcement hypothesis. Animal Behaviour 58: 995-1000.

Göth A., Vogel U. \& Curio E. 1999. The acoustic communication of the Polynesian megapode Megapodius pritchardii G.R. Gray. Zoologische Verhandelingen 327: 37-51.

Hall M.L. \& Magrath R.D. 2000. Duetting and mate-guarding in Australian magpie-larks (Grallina cyanoleuca). Behavioral Ecology and Sociobiology 47: 180-187.

HANSKI I.K. \& LAURILA A. 1993. Variation in song rate during the breeding cycle of the Chaffinch, Fringilla coelebs. Ethology 93: 161-169.

Johnstone R.F. 1995. Sexual selection, honest advertisement and the handicap principle: reviewing the evidence. Biological Reviews 70: 1-65.

Klatt P.H. \& Ritchison G. 1993. The duetting behavior of Eastern Screech-Owls. Wilson Bulletin 105: 483-489.

Korpimäki E., Lahti K., May C., Parkin G., Tolonen P. \& Wetton J. 1996. Copulatory behaviour and paternity determined by DNA fingerprint in kestrels: effects of cyclic food abundance. Animal Behaviour 51: 945-955.

Kroodsma D.E. \& Miller E.H. 1996. Ecology and evolution of acoustic communication in birds. Ithaca: Cornell University Press.

MACE R. 1988. The dawn chorus in the great tit Parus major is directly related to female fertility. Nature 330: 745-746.

Møller A.P. 1988. Spatial and temporal distribution of song in the Yellowhammer Emberiza citrinella. Ethology 78: 321-331.

Møller A.P. 1991. Why mated songbirds sing so much: mate guarding and male announcement of mate fertility status. The American Naturalist 138: 994-1014.

Morton M.L., Pereyra M.E. \& BAptista L.F. 1985. Photoperiodically induced ovarian growth in the white crowned sparrow (Zonotrichia leucophrys gambelii) and its augmentation by song. Comparative Biochemistry and Physiology (A) 80: 93-97.

Nemeth E. 1996. Different singing styles in mated and unmated Reed Buntings Emberiza schoeniclus. Ibis 138: 172-176.

Penteriani V. 1996. The Eagle Owl. Bologna: Calderini Editrice.

Penteriani V., Gallardo M. \& Cazassus H. 2000. Diurnal vocal activity of young eagle owl and its implications in detecting occupied nests. Journal of Raptor Research 34: 232235.

Penteriani V., Gallardo M. \& Roche P. 2002. Landscape structure and food supply affect eagle owl Bubo bubo density and breeding performance: a case of intra-population heterogeneity. Journal of Zoology 257: 365-372. 
Penteriani V., Gallardo M., Roche P. \& Cazassus H. 2001. Effects of landscape spatial structure and composition on the settlement of the Eagle Owl Bubo bubo in a Mediterranean habitat. Ardea 89: 331-340.

REyer H.-U. \& SCHMidL D. 1988. Helpers have little to laugh about: group structure and vocalisation in the Laughing Kookaburra Dacelo novaeguineae.Emu 88: 150-160.

Rodrigues M. 1996. Song activity in the chiffchaff: territorial defence or mate guarding? Animal Behaviour 51: 709-716.

Slagsvold T., Dale S. \& SÆtre G.-P. 1994. Dawn singing in the great tit (Parus major): mate attraction, mate guarding, or territorial defence? Behaviour 131: 115-138.

THORPE W.H. 1961. Bird song. The biology of vocal communication and expression in birds. Monographs in Experimental Biology No. 12. Cambridge: Cambridge University Press.

Whittingham L.A., TAYlor P.D. \& Robertson R.J. 1992. Confidence of paternity and male parental care. The American Naturalist 139: 1115-1125. 